\title{
Association of HLA type with pseudoexfoliation of the lens capsule
}

\author{
J S FitzSimon, A Mulvihill, S Kennedy, A Finch, L M T Collum, P Eustace
}

\begin{abstract}
Aims/Background-To identify an HLA association with pseudoexfoliation of the lens capsule to support the hypothesis that there is a genetic predisposition to pseudoexfoliation. A randomised trial would be ideal for establishing a relation but is more costly and time consuming to conduct. Case-control studies provide an alternative method of establishing a relation.

Methods-The study group comprised 128 subjects who presented to a major eye centre with pseudoexfoliation. Data from blood donors representative of the population of Ireland were used to form a control group.

Results-An HLA association with pseudoexfoliation is identified for 14 antigens. Eleven antigens (HLA A1, A33, B8, B47, B51, B53, B57, B62, DR3, DR12, and DR13) are significantly more common in the pseudoexfoliation group while three antigens (HLA B12, B17, and DR2) are significantly less common. Four HLA antigens are strongly associated, with odds ratios of over $7 \cdot 5$.

Conclusion-The strength of this HLA association is supportive evidence for a genetic component to the development of pseudoexfoliation of the lens capsule.

(Br f Ophthalmol 1996; 80: 402-404)
\end{abstract}

\section{Department of Ophthalmology, University College Dublin, Mater Misericordiae Hospital, Dublin J S FitzSimon A Mulvihill P Eustace}

Department of Ophthalmology, Royal Victoria Eye and Ear Hospital, Dublin J S FitzSimon L M T Collum

National Ophthalmic Pathology Laboratory, Royal Victoria Eye and Ear Hospital, Dublin S Kennedy

The Blood Transfusion Service Board, Dublin A Finch

Correspondence to: Professor P Eustace, Mate Misericordiae Hospital, Eccles Street, Dublin 7, Ireland.

Accepted for publication 7 February 1996
The association of HLA status and disease in humans is supportive evidence of a genetic basis for that disease. ${ }^{1}$ Well known associations are those of HLA B27 and the seronegative arthritides, and HLA B5 and Behçet's disease. Pseudoexfoliation of the lens capsule is asymptomatic but is associated with the development of glaucoma and blindness if undetected and untreated. Early identification could reduce the incidence of visual loss and blindness. It is suspected that both genetic and environmental influences are important in the development of pseudoexfoliation with and without glaucoma and that solar radiation is the most important environmental influence. ${ }^{2}$ Pseudoexfoliation or the exfoliation syndrome is a common condition seen in ophthalmology clinics in Ireland. Prevalence figures vary from $11 \%$ in a population over 60 years old, ${ }^{3}$ to $1.33 \%$ in a random study of the general population over 50 years old but without pupil dilatation. ${ }^{4}$ Given the small and homogeneous population in the Republic of Ireland, we took a unique opportunity to compare the HLA status of patients with pseudoexfoliation with the general population, knowing the two populations were unusually comparable.

Previous studies of HLA association and pseudoexfoliation have shown conflicting results. A pilot study by Eustace et $a l^{5}$ showed an increased incidence of HLA B8 in an Irish population. This study which continues the earlier work by Eustace et al is an opportunistic, prospective, controlled study of 128 subjects with pseudoexfoliation.

\section{Subjects and methods}

\section{STUDY SETTING}

This was designed as a controlled study. Subjects were drawn from all parts of the Republic of Ireland and attended the Mater Misericordiae Hospital and Royal Victoria Eye and Ear Hospital ophthalmic departments in Dublin. These are two of the largest eye hospitals in the country which function as primary, secondary, and tertiary referral centres. Patients attended with various ophthalmic disorders ranging from trivial to important.

\section{IDENTIFICATION OF STUDY SUBJECTS}

The study population consisted of 128 patients with pseudoexfoliation. Diagnosis of pseudoexfoliation was made on finding the characteristic greyish particles and film on the anterior lens capsule. Subjects were recruited for the study when pseudoexfoliation was discovered during routine examination over a period of 1 year. They underwent complete ophthalmic examination including pupil dilatation and slitlamp examination of the anterior lens capsule where this was necessary to make the diagnosis. All subjects agreed to have a blood sample for HLA analysis.

\section{IDENTIFICATION OF CONTROLS}

Data for the control group were taken from 11805 individual blood samples from blood donors ranging from 18-45 years in age. Donors were drawn from all parts of the Republic of Ireland as the Blood Transfusion Service Board is the only facility for blood banking in the country. They were all white, geographically, environmentally, and ethnically similar to the study population. We emphasise the homogeneity of the two populations. 
Table 1 Characteristics of cases and control groups

\begin{tabular}{lll}
\hline & Cases & Controls \\
\hline Age range (years) & $36-94$ & $18-45$ \\
Median age (years) & $75 \cdot 5$ & 39 \\
Mean age (years) & $75 \cdot 2$ & $32 \cdot 9$ \\
Sex (M/F) & $78 / 50$ & $51 / 49$ \\
Race & White & White \\
\hline
\end{tabular}

methods and laboratory for controls and subjects. HLA antigens of the A, B, C, and DR loci were detected by the lymphocytotoxicity method and carried out at the National Tissue Typing Reference Laboratory of the Blood Transfusion Service Board. Frequency figures for HLA status are based on 11805 individual samples. Ninety six subjects were typed for all four loci and 32 subjects were typed for loci $\mathrm{A}$, $\mathrm{B}$, and $\mathrm{C}$.

\section{STATISTICAL ANALYSIS}

To determine the statistical significance of the observed difference in HLA status between the study population and the control group, the $\chi^{2}$ test was used. Statistical significance is $\mathrm{p}<0.05$.

p Values were not corrected in order to avoid type II errors. ${ }^{6}$ The odds ratio is stated for each antigen with $95 \%$ confidence intervals. An SAS computer program was used to calculate odds ratios. In order to avoid generating infinite odds ratios with empty cells 0.5 was added to zero cells to obtain an estimate.

\section{Results}

The study group consisted of 78 males and 50 females and all were over 36 years old (Table 1). In all, 94 histocompatibility antigens were typed. Fourteen antigens of a total of 94 were found to be significantly associated with pseudoexfoliation. All others had no significant association. Eleven antigens (HLA A1, A33, B8, B47, B51, B53, B57, B62, DR3, DR12, DR13) were significantly more common in pseudoexfoliation than in the general population (Table 2), while three antigens (HLA B12, B17, and DR2) were significantly less common (Table 3). Odds ratios and $95 \%$ confidence intervals are provided.

The following HLA antigens were found to have no significant association with pseudoexfoliation: A00, A02, A03, A09, A10, A11, A19, A23, A24, A25, A26, A28, A29, A30, A31, A32, B00, B5, B7, B13, B14, B15, B16,

Table 2 Pseudoexfoliation is positively associated with the following $H L A$ antigens

\begin{tabular}{lrrlll}
\hline $\begin{array}{l}\text { HLA } \\
\text { antigen }\end{array}$ & $\begin{array}{l}\text { Case } \\
\text { population }\end{array}$ & $\begin{array}{l}\text { Control } \\
\text { population }\end{array}$ & $\begin{array}{l}\text { Odds } \\
\text { ratio }\end{array}$ & Probability & $\begin{array}{l}\text { Confidence } \\
\text { interval }\end{array}$ \\
\hline A01 & 67 & 4978 & $1 \cdot 5$ & $0 \cdot 02$ & $1 \cdot 1-2 \cdot 1$ \\
A33 & 1 & 12 & $7 \cdot 7$ & $0 \cdot 02$ & $1 \cdot 0-60 \cdot 0$ \\
B08 & 59 & 3876 & $1 \cdot 7$ & $0 \cdot 002$ & $1 \cdot 2-2 \cdot 5$ \\
B47 & 3 & 34 & $8 \cdot 3$ & $0 \cdot 0005$ & $2 \cdot 5-27 \cdot 4$ \\
B51 & 8 & 168 & $4 \cdot 6$ & $0 \cdot 0005$ & $2 \cdot 2-9 \cdot 6$ \\
B53 & 1 & 12 & $7 \cdot 7$ & $0 \cdot 02$ & $1 \cdot 0-60 \cdot 0$ \\
B57 & 12 & 431 & $2 \cdot 7$ & $0 \cdot 001$ & $1 \cdot 5-5 \cdot 0$ \\
B62 & 10 & 485 & $2 \cdot 0$ & $0 \cdot 037$ & $1 \cdot 0-3 \cdot 8$ \\
DR03 & 44 & 1979 & $1 \cdot 6$ & $0 \cdot 03$ & $1 \cdot 0-2 \cdot 3$ \\
DR12 & 5 & 41 & $7 \cdot 5$ & $0 \cdot 0005$ & $2 \cdot 9-19 \cdot 4$ \\
DR13 & 8 & 73 & 6.9 & $0 \cdot 0005$ & $3 \cdot 2-14 \cdot 7$ \\
\hline
\end{tabular}

Table 3 HLA antigens with a negative association with pseudoexfoliation

\begin{tabular}{llllll}
\hline $\begin{array}{l}\text { HLA } \\
\text { antigen }\end{array}$ & $\begin{array}{l}\text { Case } \\
\text { population }\end{array}$ & $\begin{array}{l}\text { Control } \\
\text { population }\end{array}$ & $\begin{array}{l}\text { Odds } \\
\text { ratio }\end{array}$ & Probability & $\begin{array}{l}\text { Confidence } \\
\text { interval }\end{array}$ \\
\hline B12 & 2 & 1135 & 0.1 & 0.002 & $0.03-0.6$ \\
B17 & 2 & 692 & 0.3 & 0.039 & $0.06-1.03$ \\
DR02 & 19 & 1714 & 0.6 & 0.024 & $0.34-0.93$
\end{tabular}

$\mathrm{B} 18, \mathrm{~B} 21, \mathrm{~B} 22, \mathrm{~B} 27, \mathrm{~B} 35, \mathrm{~B} 37, \mathrm{~B} 38, \mathrm{~B} 39$, B40, B41, B44, B45, B49, B50, B52, B54, B55, B56, B58, B60, B61, B63, B70, DR00, DR1, DR4, DR5, DR6, DR7, DR8, DR9, DR10, DR11, DR14, DR15, DR16, DR17, DR18.

\section{Discussion}

We identified 14 HLA antigens which are significantly associated with pseudoexfoliation from a total of $94 \mathrm{HLA}$ antigens. We note the occurrence of HLA A1 and B8 in combination and that this is the best known example of linkage disequilibrium in white populations. ${ }^{9} \mathrm{We}$ confirm the finding from the pilot study in the same population of an association between pseudoexfoliation and HLA B8. Three antigens were found to be significantly less common in subjects with pseudoexfoliation than the control group and we speculate that these haplotypes may confer some protective effect on these individuals. Further studies in different populations are needed to confirm these findings.

Among those antigens found more commonly in the pseudoexfoliation group than in the general population, the strongest and most statistically significant associations appear to be with HLA A33, B47, B53, and DR12. With the data available at present it has not been possible to look at combinations of HLA antigens or their frequency in the control and study populations.

Pseudoexfoliation shows a marked worldwide variation being common in Scandinavian countries, Ireland, and among the Bantu people in South Africa. ${ }^{10} \mathrm{~A}$ multifactorial inheritance pattern incorporating environmental effects may influence this. Solar radiation may be the most important environmental influence. ${ }^{2}$ In this study we sought evidence for a genetic influence. A positive association with the HLA system lends support to the genetic inheritance theory as either there is a direct susceptibility to disease in the presence of a certain HLA antigen or a genetically determined factor linked to the HLA antigen confers disease susceptibility on the individual. 69

Common sources of error in studying HLA antigens in different populations are small sample numbers, different ethnic and environmental factors in cases and control groups, familial clustering in cases and control groups, technical laboratory problems with antisera, and the arbitrary application of statistical methods. ${ }^{6}$ It is known that antigen frequencies vary with geographic location and in groups which may be genetically isolated. In population based studies with HLA antigens, chance associations may arise owing to the large 
Table 4 HLA antigens associated with pseudoexfoliation in previous studies

Olivius and Polland ${ }^{7}$ : Bw35, not confirmed in this study. Eustace et $\mathrm{al}^{5}: \mathrm{B} 8$, relative risk $=2 \cdot 46, \mathrm{p}<0.05$.

Slagsvold and Nordhagen 8 : no association, not confirmed in this study.

number of variables tested at the same time. Linkage disequilibrium may result in linked HLA associations being found to be more common and can provide spurious statistical associations. In the present study group we typed 96 patients for all four loci and 32 for three loci from September 1992 to March 1993. Control and study groups are similar in race, geographic distribution, sex, and environment and to the best of our knowledge the study group contained no family relations. All HLA typing was done in the same laboratory.

Possible sources of bias are that subjects were identified from two referral centres and the control population of blood donors did not undergo ophthalmic examination. As the prevalence of pseudoexfoliation in the general population over 40 years old is known to be $1 \cdot 33 \%{ }^{4}$ it is possible that some individuals in the control group may have had undetected pseudoexfoliation but this would bias towards the null hypothesis. The control group were younger in age than the study group and while HLA type does not change with age, pseudoexfoliation is found with increasing frequency in older people also biasing towards the null hypothesis. It was not possible to know how many family relations were among the 11805 blood donors. In the study group the sample size and the number of tests were very large. We realised that these large numbers introduced an increased likelihood of finding some statistically significant relations, but this was an opportunistic study.

Several investigators have explored the possibility of an HLA association with pseudoexfoliation (Table 4). In 1980 Olivius and Polland typed 39 Swedish subjects with pseudoexfoliation and found a significant association with HLA Bw35. ${ }^{7}$ Eustace et al in 1980 found a significant association with HLA B8 in a study of 28 Irish subjects. ${ }^{5}$ In this study the controls were blood donors from Bristol, as Irish figures were not available. Slagsvold and Nordhagen, in 1980 in Norway, typed 43 subjects with pseudoexfoliation and 45 patients with capsular glaucoma (glaucoma secondary to pseudoexfoliation) and found no significant HLA association. ${ }^{8}$ In these studies typing was performed for HLA groups $A$ and $B$ only.

As pseudoexfoliation is associated with development of glaucoma and blindness, studies of its prevalence and causes will clarify the risks of blindness and the ophthalmic requirements for a population, particularly in countries where pseudoexfoliation is common.

We have identified $11 \mathrm{HLA}$ antigens which are statistically significantly associated with pseudoexfoliation and three which are not. It would be presumptive to assume a causal effect at this stage but the existence of this association strengthens the genetic aspect of the multifactorial inheritance of pseudoexfoliation of the lens capsule.

The authors thank Dr Mary Codd, Department of Epidemiology, Mater Misericordiae Hospital, Dublin and Dr Lynda Sisson, Department of Epidemiology, Preventive Medicine, Mayo Clinic, Rochester, MN, USA.

1 Bodmer WF, Bodmer JG. Evolution and function of the HLA system. Br Med Bull 1978; 34: 309-16.

2 Taylor HR. Pseudoexfoliation, an environmental disease? Trans Ophthal Soc UK 1979; 99: 302.

3 Madden JG, Crowley MJ. Factors in the exfoliation syndrome. Br f Ophthalmol 1982; 66: 432-7.

4 Coffey M, Reidy A, Wormald R. Xian WX, Wright L, Courtney $P$. Prevalence of glaucoma in the west of Ireland. Br f Ophthalmol 1993; 77: 17-21.

5 Eustace P, Dwyer-Joyce P, McAuliffe-Curtin D, Kirrane S. HLA antigens in the pseudoexfoliation syndrome. Trans HLA antigens in the pseudoex

6 Margo CE, Trobe JD, Shuster J. HLA and ophthalmic disease associations: a critical review and improved method for statistical analysis. Acta Ophthalmol 1982; 60: 533-46.

7 Olivius E, Polland W. Histocompatibility (HLA) antigens in capsular glaucoma and simplex glaucoma. Acta Ophthalmol 1980; 8: 406-10.

8 Slagsvold JE, Nordhagen R. The HLA system in primary open angle glaucoma and in patients with pseudoopen angle glaucoma and in patients with pseudolopathia epitheliocapsularis). Acta Ophthalmol 1980; 58: lopathia

9 Rosenberg LE, Kidd KK. HLA and disease susceptibility: a primer. N Engl f Med 1977; 297: 1060-2.

10 Forsius $\mathrm{H}$. Exfoliation syndrome in various ethnic populations. Acta Ophthalmol (Suppl) 1988; 184: 71-85. 